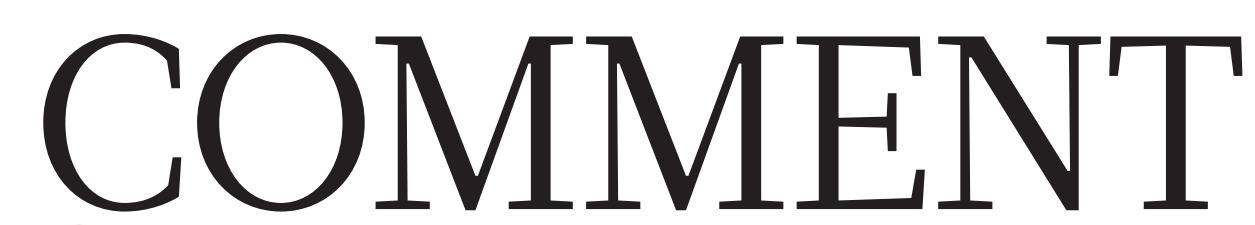

CULTURE Poet John

Burnside reflects on the demise of bees $\mathbf{p . 2 9}$
BIOTECHNOLOGY Why would we make a new mammoth even if we could? p.30
FORESTS Manage woodland for biodiversity, not just timber and carbon storage $\mathbf{p . 3 2}$
Botany Molecular techniques or not, students need to tell plants apart $\mathbf{p . 3 2}$

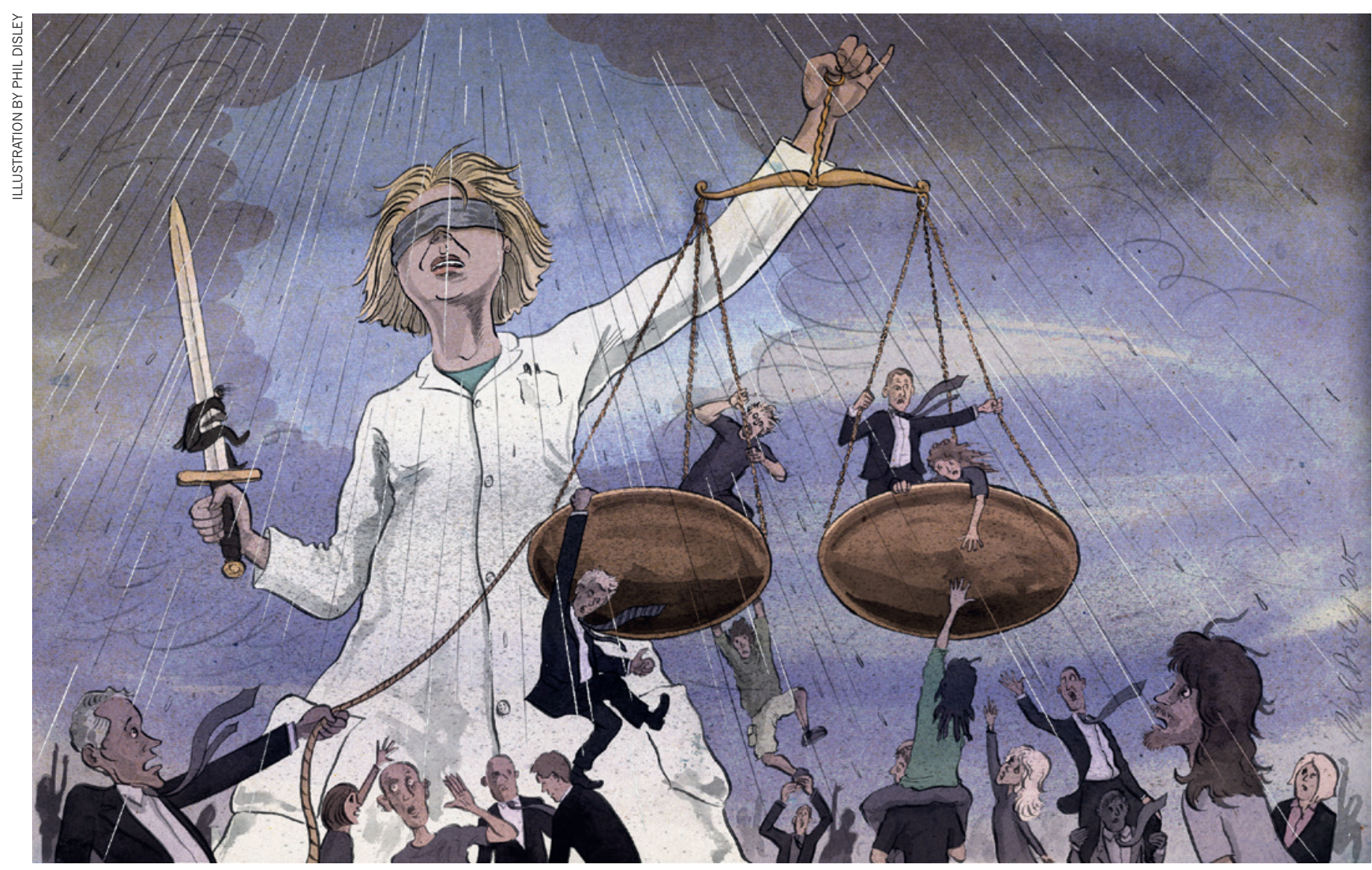

\title{
Climate advisers must maintain integrity
}

As global negotiations fail on emissions reductions, scientific advisers need to resist pressure to fit the facts to the failure, warns Oliver Geden.

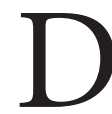
isenchantment has set in well ahead of the 21st Conference of the Parties (COP21) to the United Nations Framework Convention on Climate Change (UNFCCC) in Paris in December. Scientists, policy-makers and the public already accept that progress will not be enough to keep global average temperature rise within the $2{ }^{\circ} \mathrm{C}$ limit set at the $2010 \mathrm{UN}$ climate summit.
The negotiations' goal has become what is politically possible, not what is environmentally desirable. Gone is a focus on establishing a global, 'top down' target for stabilizing emissions or a carbon budget that is legally binding. The Paris meeting will focus on voluntary, 'bottom up' commitments by individual states to reduce emissions.

The global climate target is being watered down in the hope of getting any agreement in Paris. The $2^{\circ} \mathrm{C}$ warming limit need only be kept 'within reach'. The possibility of using 'ratcheting mechanisms' keeps hopes alive of more-ambitious policies, but such systems are unlikely to achieve the desired outcomes ${ }^{1}$. Strict measuring, reporting and verification mechanisms are yet to be agreed.

There is another casualty: scientific 
advice. Climate scientists and economists who counsel policy-makers are being pressured to extend their models and options for delivering mitigation later. This has introduced dubious concepts, such as repaying 'carbon debt' through 'negative emissions' to offset delayed mitigation - in theory.

Scientific advisers must resist pressures that undermine the integrity of climate science. Instead of spreading false optimism, they must stand firm and defend their intellectual independence, findings and recommendations - no matter how politically unpalatable ${ }^{2}$.

\section{POLITICAL WEATHER}

Climate researchers who advise policymakers feel that they have two options: be pragmatic or be ignored. They either distance themselves from the policy process by declaring that it is no longer possible to stay within a $2{ }^{\circ} \mathrm{C}$-compatible carbon budget, or they suggest practical ways to dodge carbonbudget constraints ${ }^{3}$.

Many advisers are choosing pragmatism. This can lead to paradoxical positions, as exemplified by shifting assumptions in climate economics over the past few years.

Each year, mitigation scenarios that explore policy options for transforming the global economy are more optimistic ${ }^{4}-$ and less plausible. Advisers once assumed that the global emissions peak would have to be reached before 2020 and that annual emissions-reduction rates of more than 3\% were not feasible. Those assumptions keep changing.

For example, the fourth assessment of the Intergovernmental Panel on Climate Change (IPCC), published in 2007, stated that emissions must peak by 2015 to stay within $2^{\circ} \mathrm{C}$ of warming; yet the fifth IPCC report, released last year, refers to 2030 emissions levels higher than today's that are still compatible with this limit, albeit with annual emissions-reduction rates of $6 \%$. The annual Emissions Gap Report by the United Nations Environment Programme had an original deadline of 2020 for its analysis of how to fill the gap between global emissions levels compatible with a $2{ }^{\circ} \mathrm{C}$ target and national pledges; the 2014 edition extended it to 2030 .

In both cases, climate economists got around past 'make-or-break' points for the $2{ }^{\circ} \mathrm{C}$ target by adding 'negative emissions' the removal of greenhouse gases from the atmosphere during the second half of this century. Most models assume that this can be achieved using a combination of approaches known as BECCS: bioenergy (which would require 500 million hectares of land 1.5 times the size of India) ${ }^{4}$ and carbon capture and storage, an unproven technology.

The 'carbon debt' to be paid back later can be substantial - sometimes doubling the remaining emissions quota originally

set by scientists to stay within the $2{ }^{\circ} \mathrm{Climit}$.

Meanwhile, policy-makers are delighted to hear that despite 20 years of mounting emissions, the $2{ }^{\circ} \mathrm{C}$ target is still theoretically within reach. They ignore the fine print of the IPCC reports, to climate scientists' increasing dismay.

That said, there are positive signs of researchers holding their ground. For example, the Working Group III contribution to the fifth IPCC report, which assesses mitigation options, rejected the task assigned to it by the UNFCCC: that of evaluating the adequacy of a $2{ }^{\circ} \mathrm{C}$ target compared to one

"Policy-makers view the IPCC reports mainly as a source of quotes with which to legitimize their preferences." of $1.5^{\circ} \mathrm{C}$. The IPCC turned the question straight back to policy-makers, saying that target-setting is too dependent on ethical and value judgements ${ }^{6}$.

This principled stance could pave the way for a weaker climate objective. By saying that science is incapable of judging levels of risk avoidance or intergenerational fairness, the IPCC might dilute its influence in the global target-setting process. But if scientific advisers were to refrain from demanding exact stabilization targets, the UNFCCC would no longer be able to justify a global political agreement with a simple 'science says so" ${ }^{7}$.

\section{REALITY CHECK}

Climate-science advisers should use the time before Paris to reassess their role. Do they want to inform policy-makers or support the political process? The climate policy mantra - that time is running out for $2^{\circ} \mathrm{C}$ but we can still make it if we act now - is a scientific nonsense. Advisers who shy away from saying so squander their scientific reputations and public trust in climate research ${ }^{8}$.

The scientific community must defend its independence from outside interference from government administrations and nongovernmental organizations attempting to woo scientists to back their 'just' causes, and from climate-change deniers. Inviting nonscientific stakeholders from business, government and civil society to influence research agendas ${ }^{9}$, as happens in European sustainability research, must be reconsidered to curtail the politicization of science.

At the same time, climate scientists should not overestimate their influence. They need a realistic picture of their target audience and to better understand how their expertise is used. In governments and parliaments, consistency of talk, decisions and action is more the exception than the rule. The value of expert knowledge depends mainly on its utility. Dealing with problems is more important than solving them; intentions are more important than results ${ }^{10}$.

Everyday politics is therefore dominated not by evidence-based policy-making but by attempts at 'policy-based evidence-making. For instance, policy-makers view the IPCC reports mainly as a source of quotes with which to legitimize their preferences, a practice that the IPCC should on occasion discourage.

Climate-policy advisers should align their expectations with those in other public-policy domains such as development, health, foreign and security policy ${ }^{2}$ : scientific evidence is just one of many factors affecting political decisions, such as voter preferences, available funds, competing interests and sheer pragmatics. The best that scientists can hope for is 'evidence-informed policy-making.' They are not, after all, democratically elected.

Scientific advisers should resist the temptation to be political entrepreneurs, peddling their advice by exaggerating how easy it is to transform the economy or deploy renewable technologies, for instance. Their task is to analyse critically the risks and benefits of political efforts and contribute empirically sound and sometimes unwelcome - perspectives to the global climate-policy discourse.

Oliver Geden is head of the EU Research Division at the German Institute for International and Security Affairs in Berlin, Germany. He previously worked in the policy-planning units of two German government ministries. e-mail:oliver.geden@swp-berlin.org

1. Victor, D. G. Nature Clim. Change 4, 853-855 (2014).

2. Lentsch, J. \& Weingart, P. in The Politics of Scientific Advice: Institutional Design for Quality Assurance (eds Lentsch, J. \& Weingart, P.) 3-18 (Cambridge Univ. Press, 2011).

3. Geden, O. Modifying the $2^{\circ} \mathrm{C}$ Target: Climate Policy Objectives in the Contested Terrain of Scientific Policy Advice, Political Preferences, and Rising Emissions (German Institute for International and Security Affairs, 2013).

4. Tavoni, M. \& Socolow, R. Climatic Change 118, 1-14 (2013)

5. Fuss, S. et al. Nature Clim. Change 4, 850-853 (2014).

6. Edenhofer, O. \& Kowarsch, M. Environ. Sci. Policy 51, 56-64 (2015).

7. Geden, O. \& Beck, S. Nature Clim. Change 4, 747-748 (2014).

8. Pielke, R. A. Jr The Honest Broker: Making Sense of Science in Policy and Politics (Cambridge Univ. Press, 2007).

9. Lang, D. J. et al. Sustain. Sci. 7, 25-43 (2012).

10.Brunsson, N. The Consequences of DecisionMaking (Oxford Univ. Press, 2007).

\section{CORRECTION}

The Comment 'Five priorities for the UN Sustainable Development Goals' (Y. Lu et al. Nature 520, 432-433; 2015) gave an incorrect affiliation for co-author Nebojsa Nakicenovic. He is deputy director-general of the International Institute for Applied Systems Analysis in Vienna, Austria. 